Revista Destaques Acadêmicos, Lajeado, v. 10, n. 4, 2018. ISSN 2176-3070

DOI: http://dx.doi.org/10.22410/issn.2176-3070.v10i4a2018.2023

http://www.univates.br/revistas

\title{
UTILIZAÇÃO DO RESÍDUO DE BENEFICIAMENTO DE PEDRAS PRECIOSAS NA FABRICAÇÃO DE PISOS INTERTRAVADOS DE CONCRETO
}

\author{
Larissa Toledo Dullius ${ }^{1}$, Cristiano Giovanella² , Suélen Nichel ${ }^{3}$, \\ Carolina Bernhard ${ }^{4}$, Eniz Conceição Oliveira ${ }^{5}$
}

\begin{abstract}
Resumo: O Brasil é um grande exportador de pedras preciosas e semipreciosas em seu estado bruto. Devido à falta de investimento em tecnologias adequadas, a quantidade de perdas produtivas apenas na etapa de corte das pedras é de cerca de $50 \%$ do total de matéria-prima. $\mathrm{O}$ resíduo gerado pela indústria de beneficiamento de pedras preciosas é formado por óleo, pó e pequenos pedaços de pedras. Com a dificuldade de destinação correta para esse resíduo e o grande volume gerado pela indústria, esse estudo objetiva avaliar a utilização do resíduo na fabricação de pisos intertravados de concreto em substituição à areia fina. Para tal, foi realizada a caracterização do resíduo, chamado lodo de gemas. Posteriormente, foram produzidos traços substituindo-se a areia por lodo de gemas em quantidades iguais a $2 \%, 4 \%, 6 \%, 8 \%$ e $12 \%$ sobre a massa total dos agregados. Também foi produzido um traço referência para comparação. Para avaliar a qualidade dos pisos intertravados, foram realizados os ensaios de dimensionamento, absorção de água e resistência à compressão. Ao final, a análise de resultados permitiu concluir que o lodo de gemas é um resíduo que pode ser utilizado como substituto do agregado miúdo na fabricação dos pisos intertravados de concreto, sendo o melhor desempenho apresentado nos traços em que houve a substituição da areia fina por lodo de gemas em $2 \%$ e $4 \%$.
\end{abstract}

Palavras-chave: Lodo de Gemas. Pisos intertravados. Concreto.

1 Graduanda em Engenharia Ambiental (UNIVATES). Bolsista de Iniciação Científica. E-mail: larissa.dullius@universo.univates.br

2 Mestre em Ambiente e Desenvolvimento (UNIVATES). Graduado em Química Industrial (UNIVATES). Professor do CET (UNIVATES). E-mail: giovaqmc@gmail.com

3 Graduanda em Engenharia Química (UNIVATES). Bolsista de Iniciação Científica. E-mail: suelennichel@hotmail.com

4 Graduanda em Engenharia Civil (UNIVATES). Bolsista de Iniciação Científica. E-mail: carolina1bem@hotmail.com

5 Pós-Doutoranda em Educação e Psicologia (UA). Doutora em Química (UFRGS) e mestre em Química (UFRGS). Professora do CCTEC (UNIVATES). E-mail: eniz@univates.br 


\section{INTRODUÇÃO}

Por muitos anos, os resíduos industriais foram considerados apenas subprodutos do sistema, fazendo com que a prioridade fosse destiná-los para locais distantes das cidades. Com a expansão das cidades, começaram a surgir problemas como a falta de local adequado para destinação desses resíduos, contaminação ambiental das áreas utilizadas, além de problemas de saúde da população habitante das periferias onde os resíduos eram destinados. Para sanar essa problemática, a investigação da reutilização dos resíduos do processo produtivo começou a ser realizada (DEMAJOROVIC, 1996).

O Brasil é um dos maiores exportadores mundiais de pedras preciosas e semipreciosas brutas. Em 2004 as exportações chegaram a movimentar US\$ 39.466 .865 , valor $12,63 \%$ superior ao ano anterior, no qual a comercialização no mercado externo totalizou US\$ 35.042.146. No entanto, a exportação sem beneficiamento resulta na redução de valor agregado às peças. E, neste contexto, o Brasil está na sexta posição do ranking mundial quando se trata da exportação de pedras preciosas lapidadas. Essa situação decorre das dificuldades enfrentadas pelo setor: alta geração de resíduos e dificuldade na destinação final; e utilização de tecnologias ultrapassadas, de modo a tornar a produção artesanal (COSTA, 2007). Essa baixa tecnologia ocasiona as perdas produtivas, gerando um excedente de resíduo nas etapas de corte, torneamento, lixamento e polimento. Estes resíduos são o lodo de gemas (resíduo sólido não metálico, com média de $95 \%$ de sílica em sua composição, podendo conter óleo diesel marítimo residual em sua mistura) e os cacos de gemas (pequenos pedaços de gemas que sobram do processo de corte). $\mathrm{O}$ corte das gemas é realizado em máquinas denominadas de serra caixão, que utilizam óleo diesel marítimo para lubrificação. Essa etapa acaba gerando um resíduo acinzentado escuro, que é composto por óleo, pó e pequenos restos da gema cortada (SINDELAR; BARDEN; STÜLP, 2013). Segundo Bruxel (2011), cerca de 50\% da matériaprima transforma-se em resíduo nessa etapa do processo de beneficiamento.

Atualmente, a reutilização de resíduos da cadeia produtiva vem sendo estudada. Uma das alternativas para a reutilização de resíduos são os pisos intertravados de concreto, comercialmente conhecidos como pavers, pois estes são versáteis e de fácil aplicação. O paver também é uma boa alternativa para incorporação de resíduos industriais, devendo ser investigadas adequadamente as características do resíduo quando incorporado nas diversas formulações (LOPES; BACARJI, 2014, SILVA et. al, 2017, COSTA; GUMIERI; BRANDÃO, 2014).

Desta forma, o objetivo do presente trabalho é desenvolver um piso intertravado de concreto para pavimento, substituindo parcialmente um de seus agregados naturais por lodo oriundo do processo de beneficiamento de gemas, avaliando sua qualidade final em comparação ao piso de concreto padrão, através de testes de dimensionamento, absorção de água e resistência à compressão. 


\section{MATERIAIS E MÉTODOS}

Nessa pesquisa foram fabricados pisos intertravados de concreto (pavers) com incorporação em diferentes proporções do resíduo denominado lodo de gemas, em substituição à areia fina. $\mathrm{O}$ estudo teve a parceria de duas indústrias, uma do setor de beneficiamento de gemas e a outra de produção de pisos intertravados de concreto.

O resíduo utilizado foi coletado na indústria de beneficiamento de gemas e pode ser definido como uma mistura de massa pastosa, oleosa, fina, de aparência esbranquiçada à acinzentada e com odor levemente característico de óleo diesel marítimo, utilizado no processo como lubrificante da serra de corte. O lodo passou pelo processo de tombamento em betoneira de $250 \mathrm{~L}$, marca Horbach, com adição de água para retirada do óleo excedente.

Na primeira etapa, os agregados tradicionais do piso de concreto (areia fina, média, grossa e brita $\mathrm{n}^{\circ}$ 0) e o lodo de gemas foram secos em estufa a $110^{\circ} \mathrm{C}$ durante oito horas, até a constância da massa e posteriormente submetidos a ensaios de caracterização, para então, ser realizada a formulação das dosagens experimentais dos blocos.

\subsection{Caracterização dos agregados}

Os agregados foram avaliados através de ensaios de caracterização, sendo eles: ensaio granulométrico (ABNT, 2003a), ensaio de massa unitária (ABNT, 2006), ensaio de massa específica para agregado miúdo (ABNT, 2009) e para agregado graúdo (ABNT, 2003b), teor de material pulverulento (ABNT, 2003c) e ensaio de determinação da umidade natural para agregado graúdo (ABNT, 2011a) e para agregado miúdo (ABNT, 2011b).

Também foram realizadas análises para determinação da composição mineralógica do lodo de gemas, obtida por difração de raios $X$ (DRX) em Difratômetro Bruker - D8 com goniômetro theta-thetae radiação em tubo de cobre nas condições de $40 \mathrm{kV}$ e $40 \mathrm{~mA}$ e com análise relativa ao banco de dados International Union of Cristallography. A velocidade e o intervalo de varredura do goniômetro são 1 grama de pó a 2 segundos para $0,02^{\circ}$ do goniômetro de $2^{\circ}$ a $72^{\circ} 2$ theta, respectivamente. A quantificação das fases cristalinas identificadas na amostra foi realizada pelo Método de Rietveld com GOF $=1,86$ e Rwp = 16,20 , segundo o padrão interno devido à estrutura simples e poucos picos difratados.

A composição química do lodo de gemas foi determinada por fluorescência de raios X (FRX) em equipamento Philips P2400 X'Pert com pastilha de calibração para deteç̧ão dos elementos. A espectrometria de fluorescência de raios $X$ foi usada para determinar os óxidos presentes no lodo de gemas. A amostra do resíduo foi calcinada $\left(1000 \pm 10^{\circ} \mathrm{C}\right)$ para produzir pastilhas fundidas. 


\subsection{Definição dos traços e dosagens dos materiais}

Para a definição dos traços a serem utilizados no estudo, fez-se a caracterização inicial dos agregados a serem incorporados nos pisos intertravados produzidos (TABELA 1).

Tabela 1 - Caracterização dos agregados utilizados na construção dos pisos intertravados de concreto

\begin{tabular}{|c|c|c|c|c|}
\hline MATERIAL & $\begin{array}{l}\text { MASSA } \\
\text { UNITÁRIA } \\
\left(\mathbf{k g} / \mathbf{m}^{3}\right)\end{array}$ & $\begin{array}{c}\text { MASSA } \\
\text { ESPECÍFICA } \\
\left(\mathrm{kg} / \mathrm{m}^{3}\right) \\
\end{array}$ & $\begin{array}{c}\text { MATERIAL } \\
\text { PULVERULENTO } \\
(\%)\end{array}$ & $\begin{array}{l}\text { UMIDADE } \\
(\%)\end{array}$ \\
\hline $\begin{array}{l}\text { NORMA } \\
\text { ABNT }\end{array}$ & $\begin{array}{l}\text { NBR NM } 45 \\
\quad(2006)\end{array}$ & $\begin{array}{l}\text { NBR NM } 52 \\
(2009) \\
\text { NBR NM } 53 \\
(2009)^{*} \\
\end{array}$ & NBR NM 46 (2003) & $\begin{array}{l}\text { NBR 9775 } \\
(2011) \\
\text { NBR 9939 } \\
(2011)^{*} \\
\end{array}$ \\
\hline 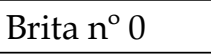 & $1566,83 \pm 0,002$ & $2935,01 \pm 0,002$ & $0,18 \pm 0,002$ & 0,12 \\
\hline Areia grossa & $1601,80 \pm 0,001$ & $2629,70 \pm 0,001$ & $0,50 \pm 0,002$ & 2,98 \\
\hline Areia média & $1547,11 \pm 0,001$ & $2636,84 \pm 0,001$ & $0,90 \pm 0,002$ & 5,11 \\
\hline Areia fina & $1572,66 \pm 0,001$ & $2697,62 \pm 0,002$ & $1,24 \pm 0,001$ & 7,57 \\
\hline $\begin{array}{l}\text { Lodo de } \\
\text { gemas }\end{array}$ & $1278,24 \pm 0,002$ & $1627,39 \pm 0,002$ & $74,84 \pm 0,005$ & 10,51 \\
\hline
\end{tabular}

* Norma ABNT para caracterização do agregado graúdo, Brita n ${ }^{\circ}$, com adaptação.

A granulometria de todos os agregados foi realizada após a secagem do material em estufa com temperatura de $105 \pm 5^{\circ} \mathrm{C}$. Além de seco, o resíduo de beneficiamento também foi moído de modo a reduzir os possíveis pedaços aglomerados remanescentes de quando se encontrava com umidade de 10,51\%.

Conforme a NBR NM 248 (ABNT, 2003a), o ensaio se limita à peneira 0,150 $\mathrm{mm}$, porém, foi acrescido da peneira de 0,075 $\mathrm{mm}$ pelo fato de limitar os agregados miúdos. $\mathrm{O}$ material passante pela peneira $0,075 \mathrm{~mm}$, visível na Figura 1, é o material pulverulento, o qual foi identificado em porcentagem através da NBR NM 46 (ABNT, 2003c), cujos resultados estão expressos na Tabela 1. Sendo assim, a partir da caracterização dos agregados, foi possível avaliar qual agregado mais se assemelha com o lodo de gemas para posterior substituição. Por se tratar de um material fino (FIGURA 1), o agregado escolhido para realização da substituição foi a areia fina. 
Figura 1 - Curva granulométrica dos agregados e do lodo de gemas

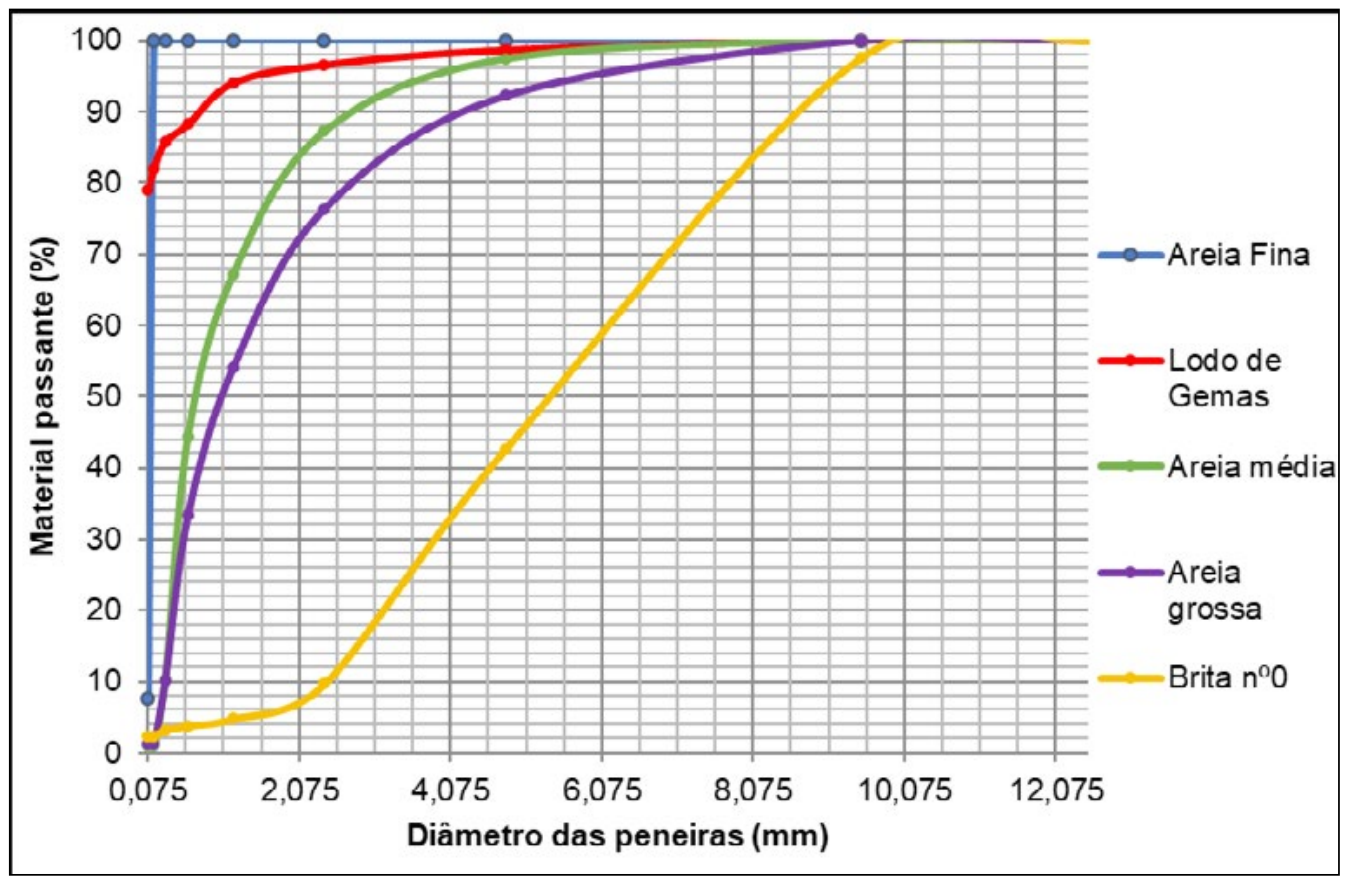

Fonte: Do Autor (2018).

Conforme pode-se observar na Figura 1, o lodo de gemas apresenta cerca de $79 \%$ de material passante na peneira $0,075 \mathrm{~mm}$. Segundo estudos de Reis e Tristão (2010), o resíduo de lodo de gemas é um material pulverulento, que deve atuar como filler, preenchendo espaços vazios do material cimentício, consequentemente aumentando sua resistência. $\mathrm{O}$ efeito filler é um efeito físico de preenchimento de vazios que ocorre devido à diminuição da porosidade total do sistema (ROMANO et al., 2008).

A etapa seguinte constituiu-se na avaliação do traço utilizado tradicionalmente pela indústria de fabricação de pisos intertravados de concreto. A partir deste, elaborou-se novos traços substituindo a areia fina por lodo de gemas, proporcionalmente à porcentagem de areia fina no bloco padrão. Os traços utilizados na pesquisa foram definidos na Tabela 2. A empresa parceira utiliza $12 \%$ de areia sobre a massa total dos agregados. 
Tabela 2-Traços estudados a partir dos dados da empresa parceira, considerando a substituição da areia fina pelo lodo de gemas em \% de massa

\begin{tabular}{l|c|r}
\hline \multicolumn{3}{c}{ \% SOBRE A MASSA TOTAL DE AREIA FINA } \\
\hline \multicolumn{1}{c|}{ TRAÇO* } & AREIA FINA & \multicolumn{1}{c}{ LODO DE GEMAS } \\
\hline Padrão & 100,00 & 0,00 \\
\hline AF10/LG2 & 83,35 & 16,65 \\
\hline AF8/LG4 & 66,67 & 33,33 \\
\hline AF6/LG6 & 50,00 & 50,00 \\
\hline AF4/LG8 & 33,33 & 66,67 \\
\hline AF0/LG12 & 0,00 & 100,00 \\
\hline
\end{tabular}

* AF10/LG2 = 10\% de areia fina e 2\% de lodo de gemas; AF8/LG4 = 8\% de areia fina e $4 \%$ de lodo de gemas; AF6/LG6 $=6 \%$ de areia fina e $6 \%$ de lodo de gemas; AF4/LG8 $=4 \%$ de areia fina e $8 \%$ de lodo de gemas; $\mathrm{AF} 0 / \mathrm{LG} 12=0 \%$ de areia fina e $12 \%$ de lodo de gemas.

As etapas de fabricação das peças seguiram o mesmo procedimento, tanto para o traço padrão da indústria, como para as dosagens experimentais. Para cada um dos traços foram fabricados 100 pavers. Estes foram fabricados em escala industrial, substituindo-se apenas a areia fina pelo lodo de gemas, nas proporções pré-definidas, não havendo nenhuma outra alteração em sua formulação (TABELA 3). As modificações foram feitas com base no traço padrão adotado pela indústria parceira.

A quantidade de materiais utilizada está representada em volume conforme indicações da indústria colaboradora. Esta representação remete ao volume de material necessário, preenchendo-se padiolas para deposição no misturador mecânico (betoneira), com base em um saco de cimento, ou seja, $50 \mathrm{~kg}$. Mesmo pouco comum tal representação é afirmada pela bibliografia da tecnologia do concreto apresentada por Petrucci (1998). Na necessidade de conhecer a quantidade de algum material em massa $(\mathrm{kg})$, deve-se dividir a quantidade dada em volume (sendo necessária a conversão de $\mathrm{L}$ para $\mathrm{m}^{3}$ ), pelo valor de massa unitária $\left(\mathrm{kg} / \mathrm{m}^{3}\right)$ apresentado na Tabela 1 (PETRUCCI, 1998). A quantidade de aditivo plastificante é a usual utilizada pela indústria para garantir a plasticidade da mistura de concreto, e a possibilidade de conformação por meio da vibro prensa. 
Tabela 3 - Dosagens dos materiais utilizados em cada traço

\begin{tabular}{l|c|c|c|c|c|r}
\hline \multicolumn{1}{c|}{ MATERIAL } & PADRÃO & $\begin{array}{c}\text { AF0/ } \\
\text { LG12 }\end{array}$ & $\begin{array}{c}\text { AF4/ } \\
\text { LG8 }\end{array}$ & $\begin{array}{c}\text { AF6/ } \\
\text { LG6 }\end{array}$ & $\begin{array}{c}\text { AF8/ } \\
\text { LG4 }\end{array}$ & $\begin{array}{c}\text { AF10/ } \\
\text { LG2 }\end{array}$ \\
\hline Cimento (kg) & 50 & 50 & 50 & 50 & 50 & 50 \\
\hline Areia fina (L) & 25 & 0 & 8,5 & 13 & 17 & 20,5 \\
\hline Areia média (L) & 50,5 & 50,5 & 50,5 & 50,5 & 50,5 & 50,5 \\
\hline Areia grossa (L) & 74 & 74 & 74 & 74 & 74 & 74 \\
\hline Brita n 0 (L) & 49 & 49 & 49 & 49 & 49 & 49 \\
\hline Lodo de gemas (L) & 0 & 31 & 21 & 15,5 & 10,5 & 5 \\
\hline Aditivo (mL) & 50 & 50 & 50 & 50 & 50 & 50 \\
\hline Água (L) & 30 & 30 & 30 & 30 & 30 & 30 \\
\hline
\end{tabular}

\subsection{Controle de qualidade}

Os pisos produzidos passaram por um controle de qualidade para avaliar seu desempenho em comparação ao piso padrão da empresa. Os ensaios realizados foram de dimensionamento, absorção de água e resistência à compressão, seguindo a norma técnica correspondente (ABNT, 2013).

O dimensionamento das peças foi realizado com paquímetro digital da marca Digimess, devidamente calibrado e de resolução 0,005 mm. Foram analisadas as dimensões de 10 amostras para cada traço.

A absorção de água utilizou uma balança de precisão da marca Marte, modelo AZB 387 de resolução 0,01 g. Para secagem das peças, utilizou-se estufa da marca Sterilifer, modelo SX 1.5 DS, com temperatura máxima de até $250^{\circ} \mathrm{C}$.

Já os testes de resistência à compressão foram realizados em prensa hidráulica da marca Emic, modelo PC200CS, com capacidade de 200 ton, carregamento na faixa de $0,5 \pm 0,2 \mathrm{MPa} / \mathrm{s}$, indicador digital e software TESC. Sendo que, para cada traço foram rompidos 10 corpos de prova na idade de 28 dias.

\section{RESULTADOS E DISCUSSÃO}

De acordo com a composição mineralógica do resíduo, obtida pela técnica de Difração de Raios X, o mineral predominante no resíduo é o quartzo, o qual é composto basicamente por dióxido de silício $\left(\mathrm{SiO}_{2}\right)$.

Os resultados da composição química do resíduo (TABELA 4), realizada através da técnica de Fluorescência de Raios X, mostram que o óxido de silício é o principal constituinte desse material, com teor de $97,43 \%$, seguido pelo óxido de ferro II $\left(\mathrm{Fe}_{2} \mathrm{O}_{3}\right)$ com teor de $0,24 \%$ e alumínio $\left(\mathrm{Al}_{2} \mathrm{O}_{3}\right)$ com teor de $0,13 \%$. 
Tabela 4 - Composição química do lodo de gemas

\begin{tabular}{l|c|c|r}
\hline \multicolumn{1}{c|}{ COMPOSTO } & TEOR (\%) & COMPOSTO & \multicolumn{1}{c}{ TEOR (\%) } \\
\hline $\mathrm{SiO}_{2}$ & 97,43 & $\mathrm{ZnO}+\mathrm{HfO}_{2}$ & $<0,1$ \\
\hline $\mathrm{F}_{2} \mathrm{O}_{3}$ & 0,24 & $\mathrm{CaO}$ & $<0,05$ \\
\hline $\mathrm{Al}_{2} \mathrm{O}_{3}$ & 0,13 & $\mathrm{~K}_{2} \mathrm{O}$ & $<0,05$ \\
\hline $\mathrm{Na}_{2} \mathrm{O}$ & 0,07 & $\mathrm{MgO}$ & $<0,05$ \\
\hline $\mathrm{Co}_{2} \mathrm{O}_{3}$ & $<0,1$ & $\mathrm{MnO}$ & $<0,05$ \\
\hline $\mathrm{BaO}$ & $<0,1$ & $\mathrm{TiO}_{2}$ & - \\
\hline $\mathrm{Cr} \mathrm{O}_{3}$ & $<0,1$ & $\mathrm{~B}_{2} \mathrm{O}_{3}$ & - \\
\hline $\mathrm{PbO}$ & $<0,1$ & $\mathrm{Li}_{2} \mathrm{O}$ & 1,95 \\
\hline $\mathrm{SrO}$ & $<0,1$ & $\mathrm{PF}^{*}$ & \\
\hline
\end{tabular}

${ }^{*} \mathrm{PF}=$ perda ao fogo.

O alto teor de óxido de silício (sílica) se assemelha à composição obtida para os resíduos de beneficiamento de ágata e ametista nos resultados obtidos por Bruxel et al. (2012). E a perda ao fogo (1,95\%) do resíduo deve-se, provavelmente, à combustão do óleo diesel presente na amostra.

\subsection{Controle de Qualidade}

Os resultados de dimensionamento dos pisos intertravados fabricados estão apresentados na Tabela 5. A verificação das dimensões é importante apenas para comprovar se a indústria colaboradora mantém um padrão de produção com base na norma vigente (ABNT, 2013). Pois, a divergência das especificações dimensionais anularia qualquer possibilidade de comercialização do produto.

Tabela 5 - Resultados do teste de dimensionamento dos pisos intertravados com seus respectivos desvios padrão

\begin{tabular}{l|c|c|c|c|c|r}
\hline \multicolumn{7}{c}{ MEDIDAS (cm) } \\
\hline TRAÇO & COMPRIMENTO & $\begin{array}{c}\text { DESVIO } \\
\text { PADRÃO }\end{array}$ & LARGURA & $\begin{array}{c}\text { DESVIO } \\
\text { PADRÃO }\end{array}$ & ALTURA & $\begin{array}{c}\text { DESVIO } \\
\text { PADR ̃̃O }\end{array}$ \\
\hline Padrão & 24,32 & 0,04 & 10,65 & 0,05 & 7,60 & 0,00 \\
\hline AF0/LG12 & 24,30 & 0,00 & 10,52 & 0,04 & 7,30 & 0,00 \\
\hline AF4/LG8 & 24,32 & 0,04 & 10,77 & 0,14 & 7,40 & 0,06 \\
\hline AF6/LG6 & 24,32 & 0,04 & 10,60 & 0,00 & 7,32 & 0,04 \\
\hline AF8/LG4 & 24,32 & 0,04 & 10,60 & 0,00 & 7,32 & 0,04 \\
\hline AF10/LG2 & 24,38 & 0,08 & 10,60 & 0,00 & 7,30 & 0,00 \\
\hline
\end{tabular}


A partir dos resultados obtidos e em comparação com a NBR 9781 (ABNT, 2013), observou-se que as peças produzidas permaneceram todas de acordo com a exigência da norma técnica, em termos de comprimento, largura e altura. A norma exige um comprimento de no máximo $25 \mathrm{~cm}$, uma largura de no mínimo $9,7 \mathrm{~cm}$ e altura de no mínimo $6 \mathrm{~cm}$. O baixo desvio padrão sugere uma moldagem eficiente do processo.

O resultado também permite afirmar que a composição química do resíduo de beneficiamento não contém compostos capazes de interagir em reações expansivas durante a hidratação do cimento. Neste caso, se fortalece o fato de que o dióxido de silício presente no material não possui fases ativas capazes de se combinar com hidróxidos alcalinos nas soluções intersticiais das reações com cimento. Caso contrário, poderiam se desenvolver reações álcalissilicato, as quais absorvem moléculas de água gerando forças expansivas (RIBEIRO et al., 2012). água.

A Figura 2 apresenta os resultados obtidos no ensaio de absorção de

Figura 2 - Resultados do ensaio de absorção de água

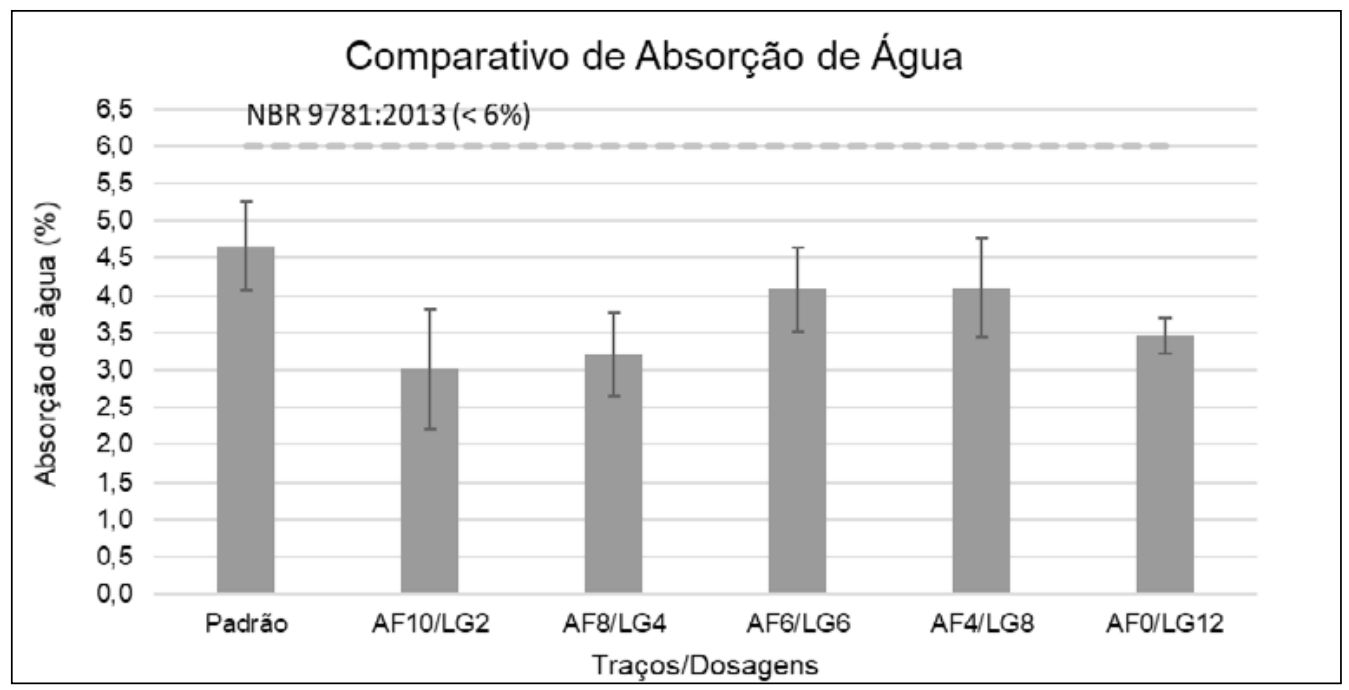

Fonte: Do Autor (2018)

A incorporação do lodo de gemas ao traço conferiu menor absorção de água que a apresentada pelos pisos de traço padrão. A média de absorção variou de 3,0\% a 4,7\%, sendo que a menor quantidade de lodo de gemas conferiu a menor absorção de água. Os traços AF10/LG2 e AF8/LG4 apresentaram os melhores resultados médios para absorção de água, e todos os traços satisfizeram os parâmetros exigidos pela norma técnica (ABNT, 2013), em que a absorção de água deve ser menor ou igual a $6 \%$. 
Na massa de produtos cimentícios, as partículas finas são responsáveis por reduzir a quantidade de vazios, o que por vez diminui a absorção e permeabilidade da água. Em contraponto, quando em excesso, os finos podem causar a exsudação da nata de cimento, por necessitar de maior quantidade de água para o preparo da mistura em decorrência da maior área superficial das partículas (SILVA; CAMPITELI, 2006). Silva e Campiteli (2006) testaram o desempenho de argamassas cimentícias com a adição de diferentes porcentagens de finos com diâmetro de grão inferior a $0,075 \mathrm{~mm}$, e constataram que para um teor de finos próximo a $20 \%$, houve redução no índice de vazios para $13,65 \%$ concomitante à diminuição da absorção de água que atingiu o valor mínimo de $19,98 \%$.

Segundo Reis e Tristão (2010), a adição de resíduo de beneficiamento de rochas ornamentais em ladrilho hidráulico causou redução no teor de absorção de água dos corpos de prova testados, porém nenhum deles atingiu a absorção mínima da norma para pisos hidráulicos.

O lodo de gemas, por se tratar de um material fino, pode ter preenchido os vazios, criando um efeito filler nos pisos, embora esse efeito não tenha sido investigado nessa pesquisa.

A Figura 3 apresenta os resultados do ensaio de resistência à compressão, realizado nos diferentes traços.

Figura 3 - Resultados do ensaio de resistência à compressão

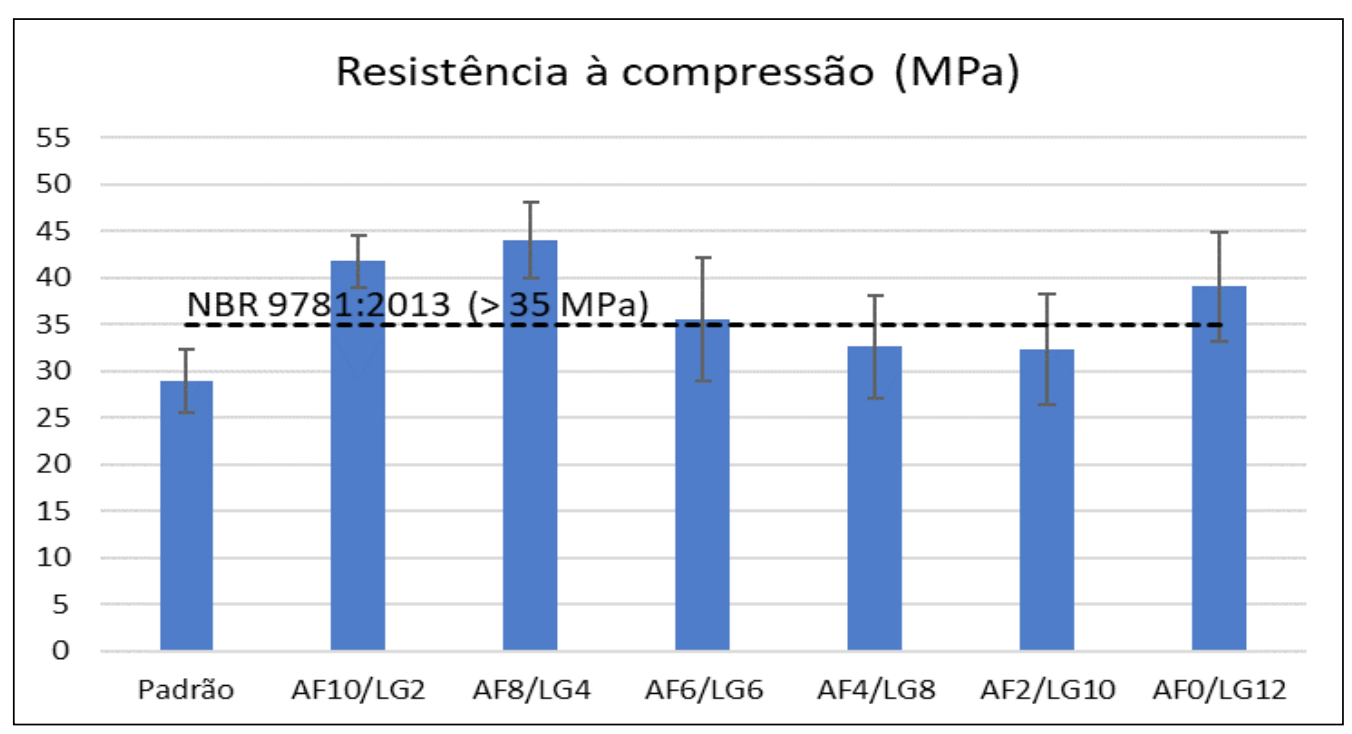

Fonte: Do Autor (2018)

Nos ensaios de resistência à compressão (FIGURA 3), em todos os traços com adição do lodo de gemas, observou-se um aumento em seus valores em 
relação ao traço padrão da indústria. Os resultados médios variaram de 28,91 MPa a 44,02 MPa, sendo que o traço AF8/LG4 apresentou o melhor resultado médio, com aumento de $52,26 \%$ da resistência em relação ao traço padrão. Os resultados médios dos traços Padrão, $\mathrm{AF} 4 / \mathrm{LG} 8$ e AF2/LG10 não atenderam às exigências da Norma Técnica NBR 9781 (ABNT, 2013) que é de uma resistência superior à $35 \mathrm{MPa}$.

Segundo estudos de López et al. (2005), o aumento da resistência à compressão pode estar relacionado de forma indireta com o preenchimento de vazios, pois existe o aumento da quantidade de partículas finas que os preenchem e tornam o material mais resistente, além de melhorar o empacotamento das partículas.

A Figura 4 apresenta a relação obtida entre os testes de absorção de água e resistência à compressão nos traços estudados para os pisos produzidos.

Figura 4 - Relação entre os resultados dos testes de absorção de água e resistência à compressão

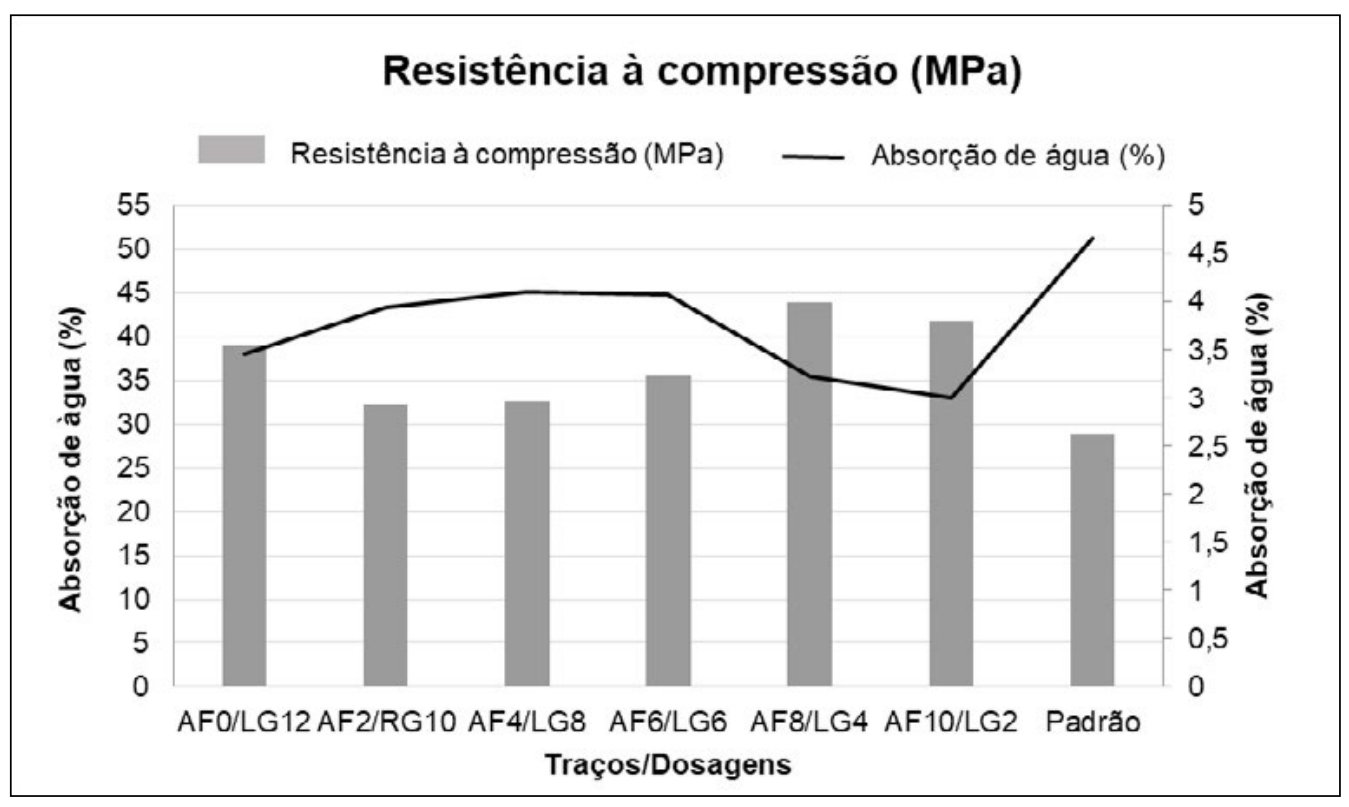

Fonte: Do Autor (2018)

A partir da relação avaliada na Figura 4, observou-se que, em sua maioria, os traços que apresentaram maior absorção de água também apresentaram menor resistência à compressão. Esse comportamento pode ser explicado pelo efeito filler (REIS; TRISTÃO, 2010), que ao preencher melhor os vazios do concreto, dificulta a absorção de água, melhorando a resistência à compressão dos pavers. 
Os traços com melhores resultados médios no controle de qualidade foram o AF8/LG4 e o AF10/LG2, os quais apresentaram melhor desempenho quando comparados ao traço Padrão. Em relação à resistência, os traços referidos obtiveram aumento, respectivamente, de 52,26\% e $44,51 \%$. Quanto à absorção de água, a redução foi de 30,90\% e 35,40\%, respectivamente.

\section{CONCLUSÃO}

A partir do estudo realizado com os pisos produzidos substituindose parcialmente a areia fina por lodo de gemas, foi possível avaliar que esta incorporação pode ser realizada em dosagens devidamente formuladas. É importante salientar que os resultados do presente estudo se limitam aos experimentos realizados, não devendo ser considerados absolutos, uma vez que se fazem necessários estudos complementares para confirmar o desempenho da utilização do resíduo nas formulações de concreto.

O emprego do lodo de gemas nos traços apresentados trouxe melhorias nas propriedades mecânicas e físicas do produto final, como aumento da resistência à compressão, assim como a diminuição da absorção de água. Para a avaliação de segurança ambiental do produto é necessária a realização de testes específicos de lixiviação nos pisos intertravados, identificando possíveis constituintes passíveis de contaminação.

No panorama de desenvolvimento sustentável atual, a ação de reaproveitar um resíduo industrial é uma importante alternativa para a preservação ambiental, pois este modelo de reutilização de resíduos na cadeia produtiva contribui para a diminuição da exploração dos recursos naturais.

\section{AGRADECIMENTOS}

Às indústrias colaboradoras da pesquisa, ao Laboratório de Tecnologias da Construção - LATEC/UNIVATES e ao CNPq.

\section{REFERÊNCIAS}

ASSOCIAÇÃO BRASILEIRA DE NORMAS TÉCNICAS. NBR NM 248: Agregados Determinação da composição granulométrica. Rio de Janeiro: ABNT, 2003a.

. NBR NM 45: Agregados - Determinação da massa unitária e do volume de vazios. Rio de Janeiro, 2006.

NBR NM 52: Agregado miúdo - Determinação de massa específica e massa específica aparente. Rio de Janeiro, RJ, 2009.

. NBR NM 53: Agregado graúdo - Determinação de massa específica, massa específica aparente e absorção de água. Rio de Janeiro, RJ, 2003b. 
NBR NM 46: Agregados - Determinação do material fino que passa através da peneira $75 \mu \mathrm{m}$, por lavagem. Rio de Janeiro, RJ, 2003c.

. NBR 9939: Agregado graúdo - Determinação do teor de umidade total Método de ensaio. Rio de Janeiro, RJ, 2011a.

NBR 9775: Agregado miúdo - Determinação do teor de umidade superficial por meio do frasco de Chapman - Método de ensaio. Rio de Janeiro, RJ, 2011b.

NBR 9781: Peças de concreto para pavimentação - Especificação e métodos de ensaio. Rio de Janeiro, RJ, 2013.

BRUXEL, F. R. A problemática dos resíduos provenientes do setor de gemas: avaliação da incorporação de lodo de gemas na massa cerâmica. Dissertação (Mestrado em Ambiente e Desenvolvimento). UNIVATES, Lajeado, RS, Brasil, 2011.

BRUXEL, F. R., OLIVEIRA, E. C., STULP, S., MULLER, C. S., ETCHEPARE, H. D. Estudo da adição de resíduo (lodo) de gemas na massa cerâmica vermelha. Cerâmica, v. 58, n. 346, pp. 211-215. Abr./Jun. 2012.

COSTA, M. Beneficiamento de pedras preciosas no Vale do Taquari - Diagnóstico e modelo para análise e redução de perdas nos processos produtivos. Dissertação (Mestrado em Engenharia). UFRGS, Porto Alegre, Brasil, 2007.

COSTA, A. V., GUMIERI, A. G., BRANDÃO, P. R. G. Interlocking concrete blocks produced with sinter-feed tailings. Revista Ibracon de Estruturas e Materiais, v. 7, n. 2, pp. 228-259, Abr. 2014.

DEMAJOROVIC, J., A evolução dos modelos de gestão de resíduos sólidos e seus instrumentos. Cadernos Fundap, v. 20, pp. 47-68, 1996.

LOPES, R. C., BACARJI, E., "Pisos intertravados com a incorporação de resíduos minerais", Revista Eletrônica de Engenharia Civil, v. 9, n. 1, pp. 22-36, Ago. 2014.

LÓPEZ, D. A. R., AZEVEDO, C. A. P., NETO, E. B., Avaliação das propriedades físicas e mecânicas de concretos produzidos com vidro cominuído como agregado fino, Cerâmica. v. 51, n. 320, pp. 318-324, out/dez, 2005.

PETRUCCI, E. G. R. Concreto de cimento Portland. 13. ed. Rio de Janeiro: Globo, 1998.

REIS, A. S., TRISTÃO, F. A. Ladrilho hidráulico piso tátil com adição de resíduo de beneficiamento de rochas ornamentais. Revista Ibracon de Estruturas e Materiais, v. 3, n. 4, pp. 390-419, Dez. 2010.

RIBEIRO, D. V., SILVA, A. M. S., LABRINCHA, J. A., MORELLI, M. R. Estudo das reações álcalis-sílica associadas ao uso da lama vermelha em argamassas colantes e de revestimento, Cerâmica, v. 58, n. 346, pp. 90-98, abr/jun. 2012. 
ROMANO, R. C. O., SCHREURS, H., JOHN, V. M., PILEGGI, R. G. Influência da técnica de dispersão nas propriedades de sílica ativa. Cerâmica, v. 54, n. 332, pp. 456461. Out/Dez 2008.

SILVA, F. M., VAZ, V. V., BARBOSA, L. A. G., LINTZ R. C. C. Avaliação da resistência mecânica de pisos intertravados de concreto sustentáveis (PICS). Matéria, v. 22, n. 1, e11778, 2017.

SILVA, N. G., CAMPITELI, V. C. Influência dos finos e da cal nas propriedades das argamassas. XI ENTAC. Ago. 2006.

SIMIELI, D., MIZUMOTO, C., SEGANTINI, A. A. S., SALLES, F. M. Utilização de agregados reciclados em pavimentos intertravados. Exacta, v. 5, n. 2, pp. 231-241, Jul./ Dez. 2007.

SINDELAR, F.C., BARDEN, J. E., STULP, S. Análise da Geração de Resíduos em uma Indústria Beneficiadora de Gemas: Um Estudo de Caso Visando o Reuso. In: 4th INTERNATIONAL WORKSHOP - ADVANCES IN CLEANER PRODUCTION, São Paulo, Anais..., 22-24 Maio 2013. 